\title{
O CORPO NEGRO COMO LÓCUS DA NEGAÇÃO DA IDENTIDADE
}

\author{
THE BLACK BODY AS IDENTITY DENIAL LOCUS
}

\author{
Geniane Diamante FERREIRA ${ }^{1}$ \\ Érica Fernandes ALVES ${ }^{2}$
}

\begin{abstract}
Resumo: O corpo negro sempre foi, desde o momento de encontro do conquistador e dos povos nãobrancos, e ainda é a base para as inserções do racismo e discriminação na sociedade. Em se tratando do corpo negro feminino, salienta-se que ele produz o discurso da sensualização, do desejo e da libido e observamos que a aceitação dele como algo indiferente ao caráter das mulheres ainda é um impasse para que as relações humanas sejam igualitárias. Desse modo, a sociedade, encabeçada pela mídia e indústrias de cosméticos e de moda, transmite aos indivíduos uma dura regra que exclui, diversas vezes, as características dos corpos negros como um padrão de beleza: os cabelos encaracolados são rotulados como 'ruins' ou 'rebeldes', estando sempre sujeitos aos alisamentos e clareamentos; os traços negros devem ser suavizados pela maquiagem que suaviza os narizes alargados e lábios muito volumosos; a pele negra é branqueada pela maquiagem que insiste em esconder o escuro e valorizar o tom claro, a moda destinada ao público negro, muitas vezes, é imbuída da ideologia do exótico, do falso multicultural. Tudo isso faz com que o negro tenha dificuldades em aceitar sua negritude, a ponto de buscar incessantemente o branqueamento para que possa pertencer à sociedade que prega, ainda hoje, a eugenia. Assim sendo, este trabalho tem por objetivo analisar dois poemas em língua inglesa que discutem a questão da imposição do branqueamento e o apagamento das características dos corpos negros como meio de aceitação na sociedade, a saber: "Kinky Hair Blues", de Una Marson e "if your complexion is a mess", de Harryette Mullen. A metodologia se baseia na discussão e aplicação das teorias sobre racismo, discriminação e identidade desenvolvidas por Hooks, Davies, Hall, entre outros. Os resultados revelam que o corpo se figura como lócus da construção da identidade do negro, porém, ele deve negar sua cor e sua identidade para que tenha condições de pertencer à sociedade em que está inserido.
\end{abstract}

Palavras-chave: Corpo. Negro. Mulher. Identidade. Negação.

Abstract: The black body has always been, from the time of the encounter of the conqueror and the non-white peoples, and is still the basis for the insertions of racism and discrimination in society. In the case of the female black body, it is emphasized that it produces the discourse of seduction, desire and libido, and we observe that its acceptance as something indifferent to the character of women is still an impasse for human relations to be egalitarian. Thus, society, headed by the media and cosmetics and fashion industries, conveys to individuals a harsh rule that often excludes the characteristics of black bodies as a pattern of beauty: curly hair is labeled 'bad' or 'rebel', always being subject to smoothing and whitening; the black features should be softened by the makeup that softens the broad noses and very bulky lips; the black skin is bleached by the makeup that insists on hiding the dark color and appreciating the light tone, the fashion destined for the black public is often imbued with the ideology of the exotic, the false multicultural. All this makes the Negro have difficulties in accepting his blackness, to the point of constantly seeking whitening so that he can belong to the society that still preaches eugenics. Thus, this work aims to analyze two poems in English that discuss the question of imposing whitening and erasing the characteristics of black bodies as a means of acceptance in society, namely: "Kinky Hair Blues", by Una Marson and "if your complexion is a mess", by Harryette Mullen. The methodology is based on the discussion and application of the theories on racism, discrimination, and identity developed

\footnotetext{
${ }^{1}$ Doutora em Letras pela Universidade Estadual de Maringá. Professora adjunta do DLM/UEM. E-mail: <efalves@uem.br>.

${ }^{2}$ Doutoranda em Letras pela Universidade Estadual de Maringá. Professora assistente do DLM/UEM. E-mail: <geniane.ferreira@uol.com.br>.
} 
by, Hooks, Davies, Hall, among others. The results reveal that the body is the locus of the construction of the identity of the Negro, but he/she must deny its color and identity so that they can belong to the society in which are inserted.

Keywords: Body. Black. Woman. Identity. Denial.

\section{Introdução}

Os poemas "Kinky Hair Blues" e "if your complexion is a mess", respectivamente de Una Marson e Harryette Mullen, como já mencionado, são objeto de estudo neste trabalho. As personagens de ambos os poemas são mulheres e o fato de as autoras das obras selecionadas também o serem é fator relevante para nossa análise, uma vez que temos vozes femininas acerca de suas vivências.

Una Marson (1905 - 1965) nasceu em Santa Cruz, Jamaica, foi ativista, dedicando-se a causas como a igualdade de gênero e de raça, e escritora. Marson mudou-se para a Inglaterra em 1932 e trabalhou para a BBC durante a Segunda Guerra Mundial, comandando o programa "Vozes Caribenhas". Assim, apesar de produzir programas, ela escreveu, em sua maioria, poesias (Tropic reveries, 1930; Heights and depths, 1932; Moth and the star, 1937 e Towards the stars, 1945) e peças (At what a price, 1933; London calling, 1938 e Pocomania, 1938). A peça At what a price? foi a primeira apresentada com elenco de atores e diretor negros produzida em Londres. Em 2011 a editora Peepal Three Press, lançou uma coletânea de poemas da autora, Selected poems. Una foi uma das autoras que mais contribuiu para a literatura caribenha na primeira metade do século XX. Hoje ela é reconhecida como a maior poeta (mulher) do Caribe.

Harryette Mullen (1953) nasceu no Alabama e cresceu no Texas e hoje é professora de inglês, literatura afro-americana e escrita criativa na Universidade da Califórnia em L.A. e escritora. Seu trabalho é centrado na tradição africana, especialmente na representação da mulher negra. Escreveu nove livros de poemas: Tree tall woman, 1981; Trimmings, 1991; $S^{*} P e R M^{* *} K^{*} T, 1992 ;$ Muse \& drudge, 1995; Sleeping with the dictionary, 2002; Blues baby, 2002; Recyclopedia: Trimmings, $S * P e R M^{* *} K^{*} T$, Muse and Drudge, 2006; Urban tumbleweed: notes from a tanka diary, 2013; Broken glish: five prose poems, 2013 e muitos ensaios e livros de crítica literária. Entre outros, em 2009 recebeu o prêmio da Academy of American Poets Fellowship.

Procuramos, por meio desta análise, traçar um paralelo entre as ideias veiculadas em cada um dos poemas que versam sobre a negação da identidade negra em prol do branqueamento imposto pela sociedade aliada à indústria da beleza. 


\section{A identidade}

Segundo Hall (2006), o conceito de identidade é "demasiadamente complexo, muito pouco desenvolvido e muito pouco compreendido na ciência social contemporânea" (p. 8).

Ainda assim, muitos autores escreveram e escrevem sobre o tema e, apesar de ainda haver muito a ser debatido, muita coisa já se pode depreender acerca da identidade. O que já sabemos é que a dificuldade da apreensão do tema vem do fato de que a identidade é algo incessantemente mutável, ou, nas palavras de Bauman (2005), líquido.

Com a convivência com os muitos diferentes, o mundo tornou-se uma composição de fragmentos mal coordenados e existências individuais que são fatiadas em episódios fragilmente conectados. Segundo Bauman,

\footnotetext{
atualmente é mais difícil esconder essa verdade do que no início da era moderna. As forças mais determinadas a ocultá-la perderam o interesse [...] e estão contentes com a tarefa de encontrar ou construir uma identidade para nós, homens, mulheres [...]. A fragilidade e a condição eternamente provisória da identidade não podem mais ser ocultadas. (BAUMAN, 2005, p. 22).
}

Além da falta de perenidade, Hall afirma que as identidades estão em declínio, fragmentadas e passando por uma crise devido à descentração no aspecto cultural, social e até de si mesmas. Segundo ele, as identidades modernas estão sendo cindidas e, consequentemente, o próprio conceito de identidade tem se tornado cada vez mais complexo e pouco compreendido dado o processo tão fundamental e abrangente por que passa (HALL, 2006).

"A identidade é realmente algo formado, ao longo do tempo, através de processos inconscientes, e não algo inato, existente na consciência no momento do nascimento" (HALL, 2006, p. 38). Então Hall, assim como Bauman, coloca a identidade como algo a ser construído infinitamente. Ocorre que as relações humanas são ambivalentes, dando segurança ou liberdade, contato ou distância e uma identidade coesa e fixa seria um fardo, pois ceifaria a liberdade de escolha.

O fato é que as comunidades se tornaram pontos de junção fundidos por diferentes ideias e princípios que também vão se modificando com o tempo (estruturas líquidas, como dissemos, nas palavras de Bauman), a identidade torna-se também problemática. Esta já não é sólida, mas cindida, nem é tampouco garantida por toda uma vida.

Deste modo, este não é um assunto que possamos olhar de forma rasa, "Não se trata da forma binária de diferença entre o que é absolutamente o mesmo e o que é absolutamente o “Outro". É uma "onda" de similaridades e diferenças, que recusa a divisão em oposições binárias fixas" (HALL, 2003, p. 58). 
A identidade do indivíduo, sendo um processo, está sob pressão para modificar-se a todo instante: "Uma vez que a identidade é um processo, o que temos é um campo de discursos, matrizes de significados, narrativas de si e outros e configuração de memórias que, uma vez em circulação, fornecem uma base para identificação" (BRAH. 2005, p. 243) 3 .

Como conclui Hall (2003, p. 154), temos hoje a premente "[...] necessidade de se pensar a unidade com a diferença; a diferença em uma unidade complexa, sem que isso implique o privilégio da diferença em si”.

Podemos citar ainda Bhabha, que fala sobre as condições em que se dá a construção da autoridade social e do processo de identificação: "existir é ser chamado à existência em relação a uma alteridade, seu olhar ou lócus"; "o próprio lugar da identificação, retido na tensão da demanda e do desejo, é um espaço de cisão" e "a identificação é sempre a produção de uma imagem de identidade e a transformação do sujeito ao assumir aquela imagem" (BHABHA, 1998, p. 76).

As personagens das obras sob estudo mostram isso claramente. No caso sob tela, o lócus ao qual nos referimos é o corpo feminino. Nas personagens femininas, sob foco neste trabalho, o estado da identidade 'em construção' (ou 'destruição') fica clara, conforme veremos adiante.

\section{Identidade Feminina}

As discussões teóricas sobre o papel das mulheres negras na sociedade, apesar de necessárias, dados os abusos cometidos contra elas, ainda não estão propriamente enraizadas nos meios acadêmicos e sociais. É verdade que a Crítica Feminista, desde o seu surgimento, tem buscado colaborar para a inclusão dessa pauta em sua agenda, mas o argumento ainda recai, na maioria das vezes, na posição ocupada pelas mulheres brancas, excluindo o problema eme(u)rgente que hoje as mulheres negras enfrentam devido à sua condição de escravas durante séculos.

Há aproximadamente quatro décadas, Davis, em seu intrépido Mulheres, Raça e Classe (1981) argumenta que se faz necessário elaborar um estudo para elucidar os mitos e estereótipos em torno das experiências vividas pelas mulheres negras que foram escravizadas, pois "as lições

\footnotetext{
${ }^{3}$ Todas as traduções de textos que não há versão em português foram feitas pelas autoras. Os originais dos excertos (em inglês) seguirão, respectivamente, como nota de rodapé. Do original: "Since identity is a process, what we have is a field of discourses, matrices of meanings, narratives of self and others, and configuration of memories, which, once in circulation, provide a basis for identification".
} 
que ele pode reunir sobre a era escravista trarão esclarecimentos sobre a luta atual das mulheres negras e de todas as mulheres em busca de emancipação" (DAVIS, 2016, p. 24).

Hoje, entretanto, observa-se que, embora o assunto esteja mais em voga nas esferas em questão, o papel social da mulher negra é ainda marginal. Não é necessário recorrer a pesquisas para observarmos que a mulher negra quase não aprece em papeis de destaque e de prestígio na sociedade: à frente de cargos de liderança na indústria e comércio, na política, na academia, nas letras ou nas artes. A visibilidade das atrizes negras, por exemplo, tem aumentado desproporcionalmente à da beleza eugênica imposta nas mídias, de modo geral.

Sob uma perspectiva biológica, o desprezo pelo corpo negro ainda é perene atualmente. Talvez os motivos dessa negação à beleza da mulher negra se devam à homogeneização dos escravos e escravas no que se refere a suas funções no campo do trabalho forçado. Em seu estudo sobre a mulher negra, Hooks afirma que "Em qualquer plantação com um número substancial de mulheres escravas, as mulheres negras desempenharam as mesmas tarefas que os homens negros; elas lavraram, plantaram, ceifaram colheitas" (HOOKS, 2016, p 18). Nessa perspectiva, o trabalho no campo, considerado comumente como um trabalho masculino, foi estendido à mulher negra, como se as diferenças aplicáveis aos homens e mulheres brancas fossem nulas no caso dos homens e mulheres negras. Enquanto as mulheres brancas vestiam roupas próprias para as mulheres, as mulheres negras se vestiam tal qual homens.

Em uma segunda perspectiva, a social, a mulher branca de classe média-alta desempenhava o papel de dona de casa, de mãe e esposa, evitando o contato com tarefas consideradas tipicamente masculinas, como a agricultura e a pecuária. $\mathrm{O}$ estereótipo em torno da mulher branca envolvia a questão da fragilidade e da preservação de sua beleza. O mesmo não aconteceu com a mulher negra, que servia aos propósitos de qualquer trabalho braçal que o senhor de escravos lhe impusesse. Isso se constituiu como uma eliminação do traço feminino da mulher negra comumente associado a todas as mulheres hoje - o de que o trabalho exaustivo e pesado corrói sua feminilidade e beleza.

Em se tratando da perspectiva sexual, a mulher negra também teve que enfrentar desafios em sua condição de escrava. Se por um lado, ela era masculinizada por ser uma operária, por outro, era a fonte de saciedade do desejo sexual masculino do homem branco. Além disso, a violência do estupro se caracterizava como mais uma punição a ser aplicada às escravas.

Como mulheres, as escravas eram inerentemente vulneráveis a todas as formas de coerção sexual. Enquanto as punições mais violentas impostas aos homens consistiam em açoitamentos e mutilações, as mulheres eram açoitadas, mutiladas e também estupradas. O estupro, na verdade, era uma expressão ostensiva do domínio 
econômico do proprietário e do controle do feitor sobre as mulheres negras na condição de trabalhadoras. (DAVIS, 2016, p. 26).

Devido à violência a que sempre foram submetidas, as mulheres negras, apesar da abolição da escravatura, se tornaram indivíduos estigmatizados, vítimas de sua diferença em relação ao padrão de beleza e ao papel social das mulheres brancas. Com o crescimento do capitalismo e a ascensão das indústrias de beleza voltadas à figura feminina, as mulheres negras continuam enfrentando as consequências do racismo, surgido na colonização, em torno de sua imagem.

Ao mencionarmos a imagem, nos deparamos com a questão central desse trabalho, isto é, a aparência da mulher negra. A aparência importa na medida em que a sociedade assinala a identidade dos sujeitos a partir dela. Em seu estudo sobre as diásporas, Brah alertou para o fato de que a identidade dos sujeitos não-brancos se constituía a partir da aparência desde o regime colonial:

\begin{abstract}
As aparências importavam muito no âmbito do regime colonial do poder. As aparências importavam devido à história da racialização das 'aparências'; elas importavam porque os discursos sobre o corpo eram cruciais para a constituição dos racismos. O poder racializado configura-se em hierarquias, não apenas entre as categorias de dominantes e subordinados, mas também entre eles. (BRAH, 2005, p. $3)^{4}$
\end{abstract}

Obviamente, desde a criação dessa ótica, o que perdurou foi uma ideia de que a aparência do não-branco o caracteriza como inferior, como diferente do padrão. A diferença não foi vista como enriquecedora, mas como um aparato que desqualifica o sujeito.

Labbé explica que "o corpo é o local das intersecções, um local onde violência, cura, opressão e empoderamento são expressados. É também uma tela sobre a qual os valores culturais são projetados $\left(2006\right.$, p. 104) ${ }^{5}$. Assim sendo, o corpo negro, entendido como uma representação do povo negro em si, contém uma carga de significados ambivalentes; se por um lado ele mostra a toda sociedade o fato de que essa mesma sociedade cometeu violências contra um povo inteiro durante séculos, também mostra que esse povo resistiu e carrega consigo as raízes de tradições e culturas que foram submetidas a inúmeras tentativas de apagamento.

\footnotetext{
${ }^{4}$ Do original: "Looks mattered a great deal within the colonial regimes of power. Looks mattered because of the history of the racialisation of 'looks'; they mattered because discourses about the body were crucial to the constitutions of racisms. And racialised power configures into hierarchies, not simply between the dominant and subordinate categories of people, but also among them".

${ }^{5}$ Do original: "The body is a site of intersections, a place where violence, healing, oppression, and empowerment are expressed. It is likewise a screen onto which cultural values are projected".
} 
Entretanto, quando o corpo negro, devido às inúmeras pressões sociais, tenta assimilar os valores eugênicos vigentes, hifeniza essa carga cultural.

Atualmente, considerando a indústria da beleza, o que podemos observar é a eterna procura pelo corpo, cabelo e pele ideais, sendo que o padrão é virtualmente impossível de ser alcançado, tendo em vista o uso comum do processo de photoshop em fotos de modelos e celebridades. Não é necessário mencionar que na maioria de anúncios de produtos de beleza destinados às mulheres as modelos utilizadas são brancas. Quando a mídia veicula a imagem ideal como sendo eugênica, exclui as mulheres negras do patamar da beleza - cabelo e pele negras simplesmente não se encaixam.

Inúmeros são os discursos que versam sobre a beleza negra, mas invariavelmente, essa beleza compete entre si, ou seja, raramente, as mulheres negras são vistas de igual para igual em relação às mulheres brancas. Em um estudo sobre as mulheres negras americanas, Olson chega à conclusão de que essas mulheres “[...] são apresentadas a padrões de beleza branca diariamente e são ensinadas desde a infância que, para serem bem sucedidas e amadas, elas devem recriar-se na estética de beleza branca dominante" (OLSON, 2006, p. 50) ${ }^{6}$. Observa-se aqui, o processo de assimilação.

A procura pelas inúmeras invenções da indústria da beleza é comum entre as mulheres negras considerando que sociedade vê no negro a exceção ao padrão. Alisamentos capilares, tinturas, cremes branqueadores e cirurgias estéticas são aliadas dessas mulheres na busca pela perfeição branca. A negação ao biológico se firmou na sociedade após as grandes navegações e descobertas de povos 'diferentes' há mais de quinhentos anos; porém, os estereótipos criados para engessar o não-branco na cadeia da subalternidade são alimentados dia a dia pelas mídias e pela indústria da beleza.

Figueiredo, ao discutir a questão da aparência do sujeito durante o período de colonização, argumenta que a negação, por parte do branco, de reconhecer as diferenças de cor de pele como sendo irrelevantes para a valorização do indivíduo teve efeitos psicológicos devastadores sobre o colonizado, que também passou a ver a diferença dérmica com aversão. Essa nova concepção favoreceu o processo de assimilação: "Diante da anulação do seu ser, diante do autodesprezo, o colonizado busca a assimilação, ou seja, tenta trocar de pele, adotando aquela que lhe parece cheia de atrativos: a figura do colonizador" (FIGUEIREDO, 1998, p. 66).

Aceitar a aparência pode ser uma bela bandeira erguida por organizações que visam ao respeito às diferenças, porém, na prática, aceitar a aparência e enxergar beleza onde ninguém

\footnotetext{
${ }^{6}$ Do original: "[...] are presented with white standards of beauty on a daily basis and are taught from childhood that in order to be successful and loved, they should recreate themselves into the dominant white beauty aesthetic".
} 
enxerga é algo que ainda está longe de acontecer plenamente. O racismo estrutural ainda perene na sociedade, embora mascarado por eufemismos e negações sobre a subalternidade do nãobranco, impede, muitas vezes, que a mulher negra aceite sua identidade, estando ela atrelada à sua aparência.

Olson argumenta que as escritoras negras feministas têm trabalhado em prol de descontruir o padrão de beleza branco como sendo o único a ser aceito: "Escritoras negras feministas dissipam e fraturam o olhar branco que concebe a mulher negra como não branca, e assim, não bela, e apresentam imagens ideais de mulheres negras belas e desejáveis" (OLSON, 2006, p.51) ${ }^{7}$.

Essa tentativa de subverter o que está sedimentado na sociedade desde o encontro do europeu com o não-branco se mostra das mais variadas maneiras na literatura. Nos poemas selecionados para esta análise, observamos que o fenótipo do negro não é respeitado por sua diferença ao padrão de beleza comumente aceito pela sociedade. A ideia que prevalece é a assimilação, apesar de os eu-líricos dos poemas ironizarem a imposição desse padrão. A ironia se constitui, portanto, na resistência desses sujeitos.

\section{Análise dos poemas}

O poema "Kinky Hair Blues", de Una Marson, pertence à obra The Moth and the Star, publicada em 1937. Já "if your complexion is a mess", de autoria de Harryette Mullen, é encontrado no livro Muse and Drudge, de 1995. Embora haja um amplo lapso temporal entre eles (aproximadamente 60 anos), ambos discutem a mesma questão: a aparência física da mulher negra e os conflitos dela advindos.

\section{Kinky Hair Blues}

Como o próprio nome indica, "Kinky Hair Blues" é um poema com a cadência de canção, e, não por acaso, no ritmo do blues. Embora a primeira publicação de uma canção no ritmo do blues seja atribuída ao músico Antonio Maggio, em 1908, em Nova Orleans, nenhuma data específica é citada como seu nascimento, mas hoje é pacífico que seus traços musicais são provenientes do continente africano. Além disso, as canções entoadas por escravos negros no Mississipi apresentavam elementos técnicos em comum com o blues. Outro fato inegável é que

\footnotetext{
${ }^{7}$ Do original: "Black feminist writers dissipate and fracture the white gaze that looks upon the black female as not white, and therefore not beautiful, and instead present ideal images of beautiful, desirable black women".
} 
as letras relatam experiências negativas de africanos e seus descendentes. O ritmo em si tem som de lamento, expressando tristeza. A própria palavra blue, na língua inglesa, é também usada para descrever infelicidade e angústia. Nas palavras de James Cone, “[...] o blues expressa uma perspectiva negra sobre a incongruência da vida e a tentativa de encontrar significado em uma situação repleta de contradições" (CONE, 1972 p. 115-6, apud DAVIS, 2017, p. 169). Como veremos a seguir, o eu lírico está eivado de contradições neste poema.

Deste modo, quanto à forma, o poema, assim como este tipo de música, é um canto de queixa. Ele apresenta seis estrofes de seis versos cada. Destes, há a repetição de alguns versos, dando, justamente, um ritmo musical. As rimas também se prestam a este objetivo, produzindo um som compassado quando da leitura do poema.

Ainda quanto à forma, é importante ressaltar que o texto não é escrito em inglês padrão culto. Tal fato pode ser lido tanto como uma denúncia da falta de oportunidade e acesso à educação, quanto uma forma de resistência, de subversão das palavras da língua oficial do opressor. Inúmeros são os exemplos encontrados no poema, entre eles destacamos: "gwine" para "going to"; "I's not" para "I'm not", "gals" para "girls", "dat" e "dis" respectivamente para "that" e "this".

Vemos, portanto, que a forma (ritmo, escolha dos vocábulos, variação linguística) tematiza o conteúdo, qual seja, a definição do belo ligado às características do branco e a busca do negro por esta beleza imposta, mas que nunca se satisfaz.

O eu lírico inicia o poema com uma decisão: “Gwine find a beauty shop / cause I ain't belle"8. Esta é a conclusão que ela chega já que "The boys pass me by/the say I's not swell"?.

Quanto à aparência, as características positivas que aparecem no texto são ligadas apenas à mulher branca, quais sejam: "ironed hair" (cabelo liso) e "bleaching skin" (pele clara). Além disso, a aparência física é também apensa à capacidade da mulher: "See oder young gals / so slick and smart" ${ }^{\prime 10}$. Deste modo, o eu lírico não se sente bela, tampouco capaz intelectualmente, porque apenas as "oder young gals"

Há, portanto, uma forte tensão apresentada entre sua identidade e a identidade que se espera que ela tenha. Como argumenta Olson:

O cabelo das mulheres afro-americanas tem sido, infelizmente, a vítima mais afetada dos padrões de beleza branca. O preconceito branco sobre o cabelo da mulher negra

\footnotetext{
${ }^{8}$ No caso dos poemas, seus trechos serão usados no original, em inglês, no corpo do texto e seguirão, como nota de rodapé, as traduções feitas pelas autoras. Tradução: "Vou procurar um salão de beleza, porque não sou bonita". 9 Tradução: "Os garotos passam por mim e dizem que não sou agradável”.

10 Tradução: "Vejo outras meninas tão inteligentes e espertas".

11 Tradução: "Outras meninas” (grifo nosso).
} 
reforça as concepções ocidentais que apenas cabelos lisos e sedosos são bonitos. Produtos para alisamento de cabelo que são rigorosamente direcionados para mulheres afro-americanas reforçam fortemente a crença de que o cabelo afroamericano não pode ser belo a menos que parece branco. Mesmo mulheres brancas que naturalmente têm o cabelo cacheado ou encaracolado gastam centenas de dólares alisando-o para que pareça menos negro. (OLSON, 2006, p. 51, tradução nossa) ${ }^{12}$.

Apesar de todas as investidas da sociedade contra a sua cor - tanto de aparência quanto de caráter - o eu lírico em "Kinky Hair Blues" ainda tem sua identidade, de certa forma, preservada: "Lord, 'tis you did gie me / all this kinky hair, / And I don't envy gals / what got dose locks so fair / I like me black face / and me kinky hair [...] / But nobody loves dem, I jes don't think it's fair."13

Desta forma, vemos que ainda resta auto estima ao eu lírico (gosta da sua própria face e do cabelo), mas não há reciprocidade disso na sociedade. Assim, voltamos ao que discutimos anteriormente sobre a identidade ser algo conflituoso. Há, até mesmo, a presença de resistência para tal modificação: "Hate that ironed hair / And dat bleaching skin. / But I'll be alone / If I don't fall in." 14

Assim, o eu lírico se revolta contra o que a sociedade impõe às mulheres negras: alisar o cabelo e clarear a pele. Entretanto, percebe que se não seguir este modelo, ficará à margem. Interessante notar que as palavras "ironed" e "bleaching" denotam organização e limpeza, como se o corpo negro fosse sujo e precisasse de asseio, higiene.

Neste caso, diante do contato com o Outro, vemos o confronto do eu lírico quanto a sua aparência física (e a ligação disso a seu caráter) e, também, quanto à língua (usa a do opressor, mas com a sua voz, como mencionamos) o que faz com que sua identidade seja modificada. $\mathrm{O}$ resultado desses contatos sucessivos é que tem desenhado as novas culturas dos países em condições diaspóricas e multiculturais.

Ainda, o processo de formação de identidade, além de complexo é infinito, de devir, por isso a 'onda' à que se refere Hall é contínua e ininterrupta à medida que mais conexões são feitas entre as pessoas. Além disso, com a mistura de pessoas, a ideia de pureza ainda hoje preconizada está, há muito, vencida.

\footnotetext{
12 Do original: “African American women's hair has unfortunately been the most affected victim of white beauty standards. White biases about black women's hair reinforce Western perceptions that only straight silky hair is beautiful. Hair straightening products that are rigorously marketed to African American women strongly reinforce the belief that African American hair cannot be beautiful unless it looks white. Even white women who have naturally curly or kinky hair spend hundreds of dollars to straighten it in order to look less black".

${ }^{13}$ Tradução: "Senhor, foi você quem me deu este cabelo crespo e eu não invejo as meninas que têm aquelas mechas lisas. Eu gosto do meu rosto negro e do meu cabelo crespo, mas ninguém gosta e acho que isso não é justo".

${ }^{14}$ Tradução: "Odeio aquele cabelo alisado e aquela pele esbranquiçada, mas estarei sozinha se eu não entrar nessa".
} 
Assim, vemos que a identidade, apesar de ser uma questão histórica e cultural, que mantém "contato com um núcleo imutável e atemporal, ligando ao passado o futuro e o presente numa linha ininterrupta" (HALL, 2003, p. 29), ou seja, uma tradição, ela também é moldada pelas associações entre pessoas, tanto nas relações igualitárias, quanto nas em que ocorreram expropriação, genocídio, escravidão etc.

Por fim, o eu lírico retoma a decisão do início (de procurar um salão de beleza), pois não vê outra saída, já que está à procura de um(a) parceiro(a): "I’s gwine press me hair / And bleach me skin. / What won't a gal do / Some kind of man to win." 15 Vemos, aqui, outro tipo de submissão - não somente ao branco - mas também ao homem, inclusive o negro.

“Como grupo, as mulheres negras estão em uma posição incomum nessa sociedade, pois não só estamos coletivamente na parte inferior da escada ocupacional, mas nosso status social geral é menor do que o de qualquer outro grupo." (HOOKS, 1984, p. 14) ${ }^{16}$ Daí o porquê de a mulher sofrer dupla discriminação. A mulher negra nunca ocupa a posição de opressor, o que pode ocorrer com o homem negro em relação à mulher negra. O feminismo negro é, então, fundamental, uma vez que o gênero não é o único determinante em comum entre as mulheres.

\section{If your complexion is a mess}

Como já falamos no início desta seção, "if your complexion is a mess" guarda muitas semelhanças com "Kinky Hair Blues". Quanto à forma, por exemplo, também há uma 'brincadeira' com a língua, uma vez que temos palavras em espanhol misturadas com as de inglês, já questionando a dominação da segunda sobre a primeira. A mistura denota, por assim dizer, a própria miscigenação das sociedades multiculturais de hoje.

O poema é composto de quatro estrofes com quatro versos cada. Embora haja rimas em alguns versos (mess e success; spades e shade), a maioria deles não apresenta qualquer rima. Tal forma também denota os vários tipos de escrita e aceitação delas como pertencentes a um todo. Ou seja, novamente, a mistura dos diferentes, dos Outros com os outros.

Ocorre que ambos os poemas têm como tema a aparência física da mulher negra. Assim como em "Kinky Hair Blues", há pressão para que o eu lírico mude, no caso, o cabelo e a cor da pele, temos em "if your complexion is a mess" uma crítica ainda mais direta à tal coação,

\footnotetext{
${ }^{15}$ Tradução: "Vou alisar meu cabelo e clarear a minha pele. O que uma garota não faz para ter um homem".

${ }^{16}$ Do original: "As a group, black women are in an unusual position in this society, for not only are we collectively at the bottom of the occupational ladder, but our overall social status is lower than that of any other group."
} 
tornando-se, em si, uma violência. O título (que é também o primeiro verso) e toda a primeira estrofe são categóricos em dar uma solução a um problema:

\author{
if your complexion is a mess \\ our elixir spells skin success \\ you'll have appeal bewitch be adored \\ hechizando con crema dermoblanqueadora ${ }^{17}$
}

Notemos que a palavra usada para se referir à pele negra é mess (bagunçado/sujo/em desordem), enquanto as que aludem à beleza são ligados ao branco, como o sucesso da pele clara surgida por uma mágica com creme clareador. Temos, daí, a flagrante inadequação ligada à pele negra, que precisa ser modificada; do mesmo modo como aparece no poema de Marson, em que encontramos termos como "beauty shop" (salão de beleza), "bleaching" (clareador) e “iron" (passar a ferro), por exemplo, que denotam a ideia de que o fenótipo negro necessita de limpeza e organização.

Ainda, desde a primeira estrofe e se estendendo para todo o poema, há uma crítica irônica à indústria da beleza e ao branqueamento. Palavras como "elixir spells skin success, hechizando con crema dermoblanqueadora, enlightment, pancakes pale" confessadamente denotam isso. Tal indústria cosmética vem com voz autoritária (e globalizada) com a tarefa de solucionar o problema de se ter uma pele negra, denotado por expressões como "dark, dirt, darky, color we've got in spades, melanin gives perpetual shade, cancer". A leitura que se faz aqui é, então, você tem de ser branco ou não é bem-vindo. O verso em espanhol se faz presente para estender a 'propaganda' e advertência a todos os não-brancos, dando a ideia da globalização de uma beleza padrão e uniforme.

A venda fica explícita no início da segunda estrofe: "what we sell is enlightment / nothing less than beauty itself" ${ }^{\prime 18}$. Notemos que a palavra 'enlightment' também pode ser entendida como um insight, a compreensão de algo. Ainda, a própria constituição da palavra é interessante: em (in) + lightment" ou 'clareamento'.

"Double dutch", na terceira estrofe, além de ser um jogo de pular cordas, se refere ao chocolate, ou à cor de chocolate dos negros que segue com a ideia de que estes voltem à África ("take kisses back to Africa"19).

\footnotetext{
17 Tradução: "Se seu aspecto é ruim, temos um elixir que vai como mágica fazer sua pele ter sucesso, você terá o feitiço da atração, um encantamento com creme clareador de pele".

${ }^{18}$ Tradução: "O que vendemos é iluminação, nada menos que a beleza em si".

19 Tradução: "Mandem beijos de volta para a África".
} 
O primeiro verso da quarta estrofe diz "color we've got in spades"20, o que quer dizer: 'não escolha ficar preta, porque esta cor te dá uma sombra perpétua' (“perpetual shade”). Observemos que o vocábulo 'pá' traz ideia de violência e a palavra 'sombra' traz consigo uma carga semântica negativa neste contexto. Retomando a estrofe anterior, entendemos que os negros devem escolher outra cor, já que foram mergulhados no tanque da fábrica de chocolate maluca ("they dipped you in a vat / at the wanky chocolate factory), fazendo referência ao filme "A Fantástica Fábrica de Chocolate" em que aparece cena semelhante.

A última estrofe, como já mencionamos, faz associações atrozes com a cor preta, como a melanina ligada ao câncer e, apesar de os africanos serem alegres e terem ritmos que expressam tal alegria como o soul ou funk (ou ainda outros que expressam sua cultura, como o blues em de “Kinky Hair Blues”), isso não pode salvá-los da 'doença de ser negro'.

Ao fazer isso, um dos maiores orgulhos da cultura negra, sua música, é desprezado, como sendo algo inútil. Inútil também é a tentativa de ficar branco já que pó compacto é pálido e a manteiga fica rançosa ("pancakes pale and butter can get rancid"). Temos, assim, uma mistura de resistência (crítica irônica ao discurso e à indústria cosmética branqueadora) com a mímica (a tentativa de parecer ou imitar o Outro), como Bhabha afirma

\footnotetext{
É da área entre a mímica e o escárnio, onde a missão reformadora, civilizadora é ameaçada pelo deslocamento do olhar de sua disciplina ambígua (...). O que eles partilham é o processo discursivo pelo qual o excesso ou deslizes produzidos pela ambivalência da mímica (quase o mesmo, mas não exatamente) não apenas 'rompe' o discurso, mas se transforma numa incerteza que coloca o sujeito colonial com uma presença 'parcial'. Por 'parcial' eu quero dizer 'incompleta' e 'virtual'. (BHABHA, 1998, p. 98) ${ }^{21}$.
}

Daí a busca incessante, mas que nunca se satisfaz, porque embora a indústria e a mídia imponham um padrão de beleza, a sociedade não se contenta com a pele negra maquiada e o cabelo alisado; o apagamento do corpo negro não é suficiente para a aceitação.

\footnotetext{
20 Tradução: "Temos uma pá de cores".

${ }^{21}$ Do original: "It is from this area between mimicry and mockery, where the reforming, civilizing mission is threatened by the displacing gaze of its disciplinary double (...). What they all share is a discursive process by which the excess or slippage produced by the ambivalence of mimicry (almost the same, but not quite) does not merely 'rupture' the discourse, but becomes transformed into an uncertainty which fixes the colonial subject as a 'partial' presence. By 'partial' I mean both 'incomplete' and 'virtual''. Obs.: Homi Bhabha parafraseia esta expressão com Almost the same, but not White [Quase o mesmo, mas não Branco], para se remeter à imitação do branco colonizador por parte do negro colonizado.
} 


\section{Conclusão}

Como vimos, embora tenhamos trabalhado com dois poemas distintos, tanto pela autoria, quanto pelo lapso temporal, além de apresentarem linguagem estrutural semelhante, mostrando resistência mesmo na forma, ambos debatem o mesmo tema.

"Kinky Hair Blues" foi escrito em 1937, enquanto "if your complexion is a mess" em 1995. Apesar do tempo que separa os dois textos ser relativamente longo, ambos apresentam a mesma temática. Assim, vemos que tal questão não avançou muito. Mesmo a partir da data de produção do último poema até os dias de hoje, caminhamos poucos passos.

O corpo negro ainda é a base para as inserções do racismo e discriminação na sociedade e também se figura como lócus da construção da identidade do negro, porém, ele deve negar sua cor e sua identidade para que tenha condições de pertencer à sociedade em que está inserido.

Assim, imposição de uma beleza pré-estabelecida acarreta na não-aceitação da identidade por parte do sujeito negro, já que o discurso do opressor é comprado (também literalmente, no caso da indústria cosmética). Desta forma, é importante notar, neste contexto, como as mulheres são muito mais vitimadas, uma vez que o principal foco da indústria da beleza são elas, dado o incentivo de esconder o escuro (e seus traços) e valorizar o tom claro.

Tudo isso faz com que o negro tenha dificuldades em aceitar sua negritude, a ponto de buscar incessantemente o branqueamento para que possa pertencer à sociedade que prega, ainda hoje, a eugenia.

\section{Referências}

BAUMAN, Z. Identidade: entrevista a Benedetto Vecchi. Trad. Carlos Alberto Medeiros. Rio de Janeiro: Zahar, 2005.

BHABHA, H. K. The Location of culture. London: Routledge, 1998.

BRAH, A. Cartographies of diaspora. London: Routledge, 2005.

DAVIS. A. Mulheres, raça e classe. Trad. Heci Regina Candiani. $1^{\text {a }}$ ed. - São Paulo: Boitempo, 2016.

DAVIS, A. Mulheres, cultura e política. $1^{\text {a }}$ ed. São Paulo: Boitempo, 2017.

FIGUEIREDO, E. Construção de identidades pós-coloniais na literatura antilhana. Niterói: Eduff, 1998.

HALL, S. Da diáspora - identidades e mediações. Org. Liv Sovik. Trad. Adelaine La Guardia Resende et al. Belo Horizonte: Ed. UFMG, 2003. 
HALL, S. A identidade cultural na pós-modernidade. Trad. de Thomaz Tadeu da Silva e Guacira Lopes Louro. Rio de Janeiro: DP\&A, 2006.

HOOKS, B. Feminist theory: from margin to center. South end press: 1984.

HOOKS, B. Ain't I a woman - black women and feminism. Tradução livre para a Plataforma Gueto. Plataforma Gueto, 2014. Disponível em: https://plataformagueto.files.wordpress.com/2014/12/nc3a3o-sou-eu-umamulher traduzido.pdf. Acesso em: 15 ago. 2018.

LABBÉ, J. Body. In: BEAULIEU. E. A. (ed) Writing african american women: an encyclopedia of literature by and about women of color. Westport: Greenwood Press, 2006.

MARSON, U. Kinky hair blues. In: BONNICI, Thomas. Poetry of the nineteenth and twentieth centuries: anthology of poems in English with introductory notes. Maringá: Massoni, 2004.

MULLEN, H. Muse \& drudge. Philadelphia: Singing Horse Press, 1995.

OLSON, D. C. Beauty. In: BEAULIEU. E. A. (ed) Writing african american women: an encyclopedia of literature by and about women of color. Westport: Greenwood Press, 2006.

STEINFELD, S. The Social significance of blues music. 2016. Disponível em:

https://tesi.luiss.it/17909/1/072752_STEINFELD_SUSANNA.pdf Acesso em: 06 ago. 2018.

Recebido em 31/08/2018

Aceito para publicação em 11/12/2018 